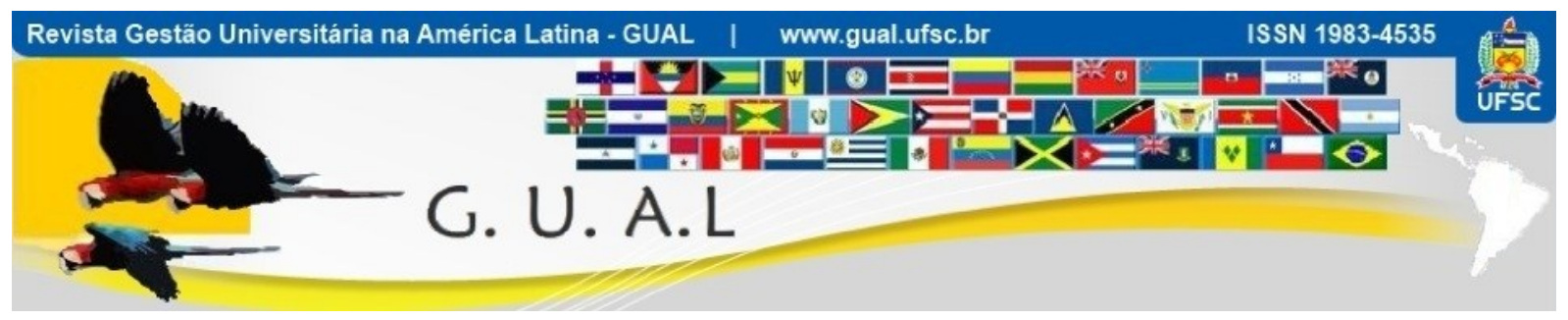

DOI: http://dx.doi.org/10.5007/1983-4535.2012v5n2p158

\title{
PESQUISA NA GRADUAÇÃO DE ADMINISTRAÇÃO: MEDIAÇÃO NECESSÁRIA AO PROCESSO ENSINO- APRENDIZAGEM
}

\author{
UNDERGRADUATE'S RESEARCH IN BUSINESS ADMINISTRATION: \\ MEDITATION REQUIRED IN THE PROCESS OF TEACHING-LEARNING
}

Mônica Mota Tassigny, Doutora

Universidade de Fortaleza - UNIFOR

monica.tass@gmail.com

Marcus Vinicius de Oliveira Brasil, Doutor Universidade Federal do Ceará - UFC mvobrasil@gmail.com

Recebido em 16/outubro/2011

Aprovado em 21/fevereiro/2012

Sistema de Avaliação: Double Blind Review

Esta obra está sob uma Licença Creative Commons Atribuição-Uso. 


\title{
RESUMO
}

A pesquisa é um processo legítimo de construção do conhecimento, e a sala de aula pode e dever ser um espaço propício a essa construção. O presente artigo, resultado de pesquisa bibliográfica, documental e da experiência prática na docência no ensino superior, tem por objetivo debater a importância da pesquisa na graduação de Administração. Nessa direção, conceitua-se a ciência como campo particular do conhecimento humano, a pesquisa como instrumento imprescindível na produção da mesma e, principalmente, como práxis formativa. Portanto, elege-se a pesquisa e suas possibilidades como fundamento do processo ensinoaprendizagem de alunos do curso de Administração, tendo o objetivo de despertar no aluno o gosto pelo conhecimento, a motivação para aprender e, sobretudo, a paixão pela pesquisa, que, como lembra Cecília Minayo (1994), consiste numa combinação harmoniosa de teoria, método e criatividade que produzem conhecimento e nos garantem prosseguir na tarefa dinâmica de tentar compreender a realidade e desvendar seus mistérios. Nessa perspectiva, procuram-se aproveitar as inúmeras possibilidades que a sala de aula oferece como local de encontro, de exposição de dúvidas, de confronto de ideias e de estabelecimento de relações. Desse modo, este artigo apresenta alguns recortes ou fragmentos dessas experiências vivenciadas com a pesquisa.

Palavras-chave: Administração. Pesquisa. Ensino. Aprendizagem.

\begin{abstract}
The research is a legitimate process of knowledge construction and the classroom can and should be an area for such construction. This article, which is the result of a bibliographic review and a documental research, also considering the practical experience in teaching in higher education, aims to discuss the importance of research in a management undergraduate course. In this sense, science is conceptualized as a particular field of human knowledge; research, as an instrument to produce it and, especially linked with formative practice, therefore, electing the research and its possibilities as the foundation of the teaching-learning of management students, with the aim to awaken in students a taste for knowledge, motivation to learn and, above all, passion for research, as noted by Cecilia Minayo (1994), who conceptualizes this process as a harmonious blend of theory, method and creativity to produce knowledge and ensures continued dynamics in the task of trying to understand the reality and unravel its mysteries. In this perspective, we seek to take advantage of numerous possibilities that offer the classroom as a meeting place, exhibition of doubt, the clash of ideas and to build relationships. Thus, this article presents some clips or fragments of these experiences with research.
\end{abstract}

Keywords: Management. Research. Education. Learning. 


\section{INTRODUÇÃO}

Parece pertinente esclarecer, no início desta exposição, que educar pela pesquisa pressupõe a necessidade de transformar os atos e atitudes diárias do professor e do aluno, ensinando e aprendendo, no contexto de uma sala de aula, num projeto e num objetivo a ambos comuns, com fundamento na pesquisa como método de constante atualização e reconstrução do conhecimento.

Se o homem não é capaz de compreender o mundo e de conscientizar-se de seu lugar, torna-se incapaz de entender a realidade que o cerca e, sobretudo, incapacita-se para agir sobre ela, reforçando a tese de que o conhecimento é uma forma hegemônica de construção de sentido sobre a realidade em que vivemos

O que queremos afirmar com isso? O campo do conhecimento se constitui como a mediação imprescindível no entendimento da realidade. Neste particular, destaca-se a ciência como ramo particular da produção do conhecimento - invocada não como instância acabada, fechada, abstrata, mas como campo de saber situado historicamente que está sempre sendo colocado em questão por seu objeto, métodos, linguagem, porque também constitui produção e comunicação do principal sujeito do globo terrestre: o homem.

Por outro lado, pelo fato de o conhecimento ser sempre situado historicamente - por não se constituir, portanto, como campo estático e imutável, mas pertencente à esfera das relações sócio-humanas -, este coloca sempre em questão o seu próprio objeto e também o sujeito homem, o qual, por sua vez, pode ser sempre questionado em sua história e em seu devir.

Toda tentativa que, sob o pretexto de cientificidade ou de rigor, quisesse enquadrar o campo da ciência (em seus fundamentos e elaboração de saber) em certezas absolutas e definitivas, colocá-la-ia, ipso facto, na impossibilidade de encontrar os meios para apreender o conhecimento como esfera existente, em constante movimento. Em outras palavras, para desvendar o universo do conhecimento humano, faz-se necessário apreendê-lo em seu aparecer e em sua historicidade, já que a interrogação própria do campo da ciência se dirige às estruturas e ao fundamento da presença do homem no mundo em suas relações com a materialidade histórica e social e com os outros homens.

Nesses termos, a ciência não é estática, mas uma manifestação do gênero humano, manifestando-se como ato relacional entre o sujeito e determinado objeto. 
Como o homem não é um ser cujas atitudes poderíamos simplesmente descrever e “coisificar", também a ciência não é um ente abstrato, mas uma produção humana existente que se torna, ela mesma, externa ao homem. Além disso, sua presença é histórica, em devir e em constante processo de superação, razão pela qual se faz objeto do conhecimento e das indagações humanas, não se estabelecendo como um saber dogmático e pronto para sempre.

Mas afinal, o que é a ciência? Podemos responder essa questão de variados pontos de vista. Do ponto de vista antropológico, podemos afirmar que, desde que existe o mundo, sempre existiu a preocupação do "homo sapiens" com o conhecimento da realidade. Desde as tribos primitivas, através da magia, dos mitos, o homem indaga sobre a realidade, a vida e a morte, o lugar dos indivíduos na organização social, enfim, sobre seus anseios e suas possibilidades de domínio sobre a materialidade social.

Do ponto de vista da filosofia, desde o séc. VI a.C. indaga-se sobre o sentido da existência, seja individual, seja coletiva. Do mesmo modo, nas odisseias, na poesia, no estilo trágico, no romance, o homem, ao escrever sobre si mesmo e sua condição, indaga também sobre o mundo, o cotidiano, o inconsciente e até mesmo sobre o próprio destino humano.

Após o séc. XVII, a ciência começa, lentamente, a desvincular-se de outras formas de indagação sobre o mundo e, a partir do séc. XIX, vai se constituindo como campo específico do conhecimento e se organizando com métodos particulares. Na sociedade ocidental, a ciência se estrutura como forma hegemônica de apreensão da realidade e, por isso, é considerada por vários pensadores como um novo mito, por sua pretensão de único caminho e critério para se chegar à verdade.

O campo do conhecimento científico foi sendo estruturado através do desenvolvimento de uma linguagem própria, com conceitos, métodos e técnicas. Usa-se uma linguagem controlada e instituída por uma comunidade científica, que controla com rigor a sua reprodução. Contudo, apesar de sua normatividade, rigor e aspiração a ser o único caminho para se chegar à verdade sobre a realidade, a ciência não acabou com a fome, com a miséria humana, com a violência, com a forma predatória de se relacionar com o meio ambiente, com a ameaça nuclear etc. Existem ainda outras controvérsias no campo científico. Sem nos aprofundar no assunto, destacaríamos o que nos interessa sobre os questionamentos e embates acerca da cientificidade das Ciências Sociais Aplicadas, terreno onde nos situamos. Uma das questões refere-se à tentativa de enquadrá-la na mesma normatividade científica de apreensão dos objetos das Ciências da Natureza. Contudo, na esfera da sociabilidade, nem tudo pode ser normatizado, generalizado, experimentado, quantificado. 
Assim, este artigo, resultado de pesquisa bibliográfica, documental e da experiência prática na docência no ensino superior, debate a importância da pesquisa na graduação de Administração. A pesquisa é desenvolvida no cotidiano na sala de aula como instrumento imprescindível na produção de conhecimento e, principalmente, como práxis formativa, realçando suas possibilidades como fundamento do processo ensino-aprendizagem de alunos do curso de Administração. Nesses termos, relatou-se a experiência da pesquisa em sala de aula e seus sentidos para além do aprendizado específico da disciplina, mas com o objetivo de despertar no aluno o gosto pelo conhecimento, a motivação para aprender e, sobretudo, a paixão pela pesquisa como mediação fundamental para se compreender a realidade e desvendar seus mistérios.

\section{O CURSO DE ADMINISTRAÇÃO}

A esfera das Ciências Socais Aplicadas trata de um objeto de estudo, de uma realidade na qual nós próprios, seres humanos, somos agentes. Tratamos igualmente de uma objetividade referenciada e situada pelo sentido da subjetividade. Nosso objeto de estudo é rico, dinâmico, base da própria relação sujeito-objeto. A cientificidade, portanto, não pode ser aprisionada com modelos e normas a serem seguidas, porque em sua essência não temos um "a priori", mas um saber que se produz em determinado momento histórico e que, por isso, tem que ser constantemente elaborado, num movimento de re-elaboração de teorias, de métodos, de princípios; isto é, faz-se necessário retificar caminhos, abandonar vias e retraçar outras. Sem cair no perigoso fosso do "relativismo", há que se aceitar em nossas investigações, contudo, os critérios da historicidade e a compreensão de que qualquer conhecimento, embora o mais aproximado do real possível, é sempre aproximativo. Pelo fato de a realidade ser sempre mais rica, contraditória e total, o conhecimento desvela apenas uma parte dessa totalidade.

A educação superior, de acordo com a Lei de Diretrizes e Bases as Educação Nacional (BRASIL, 1996) abrange:

I. Cursos sequenciais por campo do saber (formação específica e formação complementar;

II. De graduação (licenciaturas, bacharelados, curso superiores de tecnologia);

III. De pós-graduação (doutorado, mestrado, especialização, aperfeiçoamento e outros);

IV. De extensão. 
As Diretrizes Curriculares Nacionais do Curso de Graduação em Administração determinam que os cursos de bacharelado em Administração devem contemplar, em seus projetos pedagógicos e em sua organização curricular, conteúdos que revelem inter-relações com a realidade nacional e internacional. Esses conteúdos devem ser analisados segundo uma perspectiva histórica e contextualizados em sua aplicabilidade no âmbito das organizações e do meio, através da utilização de tecnologias inovadoras e que atendam aos seguintes campos interligados de formação, em conformidade com o art. $5^{\circ}$ da Resolução $n^{\circ} 1$, de 2 de fevereiro de 2004, do Conselho Nacional de Educação:

I - Conteúdos de Formação Básica: relacionados com estudos antropológicos, sociológicos, filosóficos, psicológicos, ético-profissionais, políticos, comportamentais, econômicos e contábeis, bem como os relacionados com as tecnologias da comunicação e da informação e das ciências jurídicas;

II - Conteúdos de Formação Profissional: relacionados com as áreas específicas, envolvendo teorias da administração e das organizações e a administração de recursos humanos, mercado e marketing, materiais, produção e logística, financeira e orçamentária, sistemas de informações, planejamento estratégico e serviços;

III - Conteúdos de Estudos Quantitativos e suas Tecnologias: abrangendo pesquisa operacional, teoria dos jogos, modelos matemáticos e estatísticos e aplicação de tecnologias que contribuam para a definição e utilização de estratégias e procedimentos inerentes à Administração;

IV - Conteúdos de Formação Complementar: estudos opcionais de caráter transversal e interdisciplinar para o enriquecimento do perfil do formando.

Desenvolver atividades de pesquisa, ensino e extensão em áreas estratégicas para a inclusão social e a inovação, promovendo a capacitação de novos administradores, é uma das prioridades de desenvolvimento, aliando-se ao crescimento da economia, já que gera emprego e renda, bem como a formação de novas empresas.

O desenvolvimento econômico e a reestruturação empresarial somente permitem o acesso ao mercado de trabalho de profissionais habilitados nas novas práticas competitivas, exigidas por uma economia globalizada e intensiva, em termos de conhecimentos. A globalização é a expressão das "forças de mercado"; já o termo "mundialização" introduz com mais veemência a ideia de que as instituições políticas mundiais são capazes de dominar seu movimento (CHESNAIS, 1996, p. 25).

Para Arrais Neto (2003, p. 117) a mundialização representa “os novos processos de educação-preparação da força de trabalho, tanto como capacitação técnico científica para inserção produtiva, quanto como novas formas de subsunção política e cultural à produção e à 
reprodução sociais globais [...]”. Essa lógica é reproduzida de acordo com as necessidades do capital, dando margem a novos pontos antagônicos.

A Resolução $n^{\circ}$ 1, de 2 de fevereiro de 2004, do Ministério da Educação, instituiu as Diretrizes Curriculares Nacionais dos Cursos de Graduação em Administração, a serem observadas pelas instituições de ensino superior em sua organização curricular. Essa resolução estabeleceu que a organização de cursos de Administração em todo o Brasil deve se expressar através do seu projeto pedagógico, definindo-se o perfil do formando e estabelecendo-se suas competências, habilidades e todos os outros componentes curriculares. O projeto pedagógico do curso deve estabelecer explicitamente as normas para o estágio curricular supervisionado, as atividades complementares, o sistema de avaliação, a monografia, além do regime acadêmico de oferta de disciplinas e de outros aspectos que possam tornar consistente o referido projeto.

Neste artigo, a título de exemplificação, objetivou-se trazer um panorama geral dos cursos de Administração das universidades (Tabela 1) e centros universitários de Santa Catarina que possuíam o Conceito Preliminar de Curso (CPC), que é uma espécie de uma média de diferentes medidas de qualidade dos cursos de graduação - são elas o conceito ENADE, que se refere ao desempenho dos alunos concludentes e ingressantes, o conceito IDD e as variáveis de insumo, tais como o nível de formação do corpo docente, a infraestrutura e o programa pedagógico (formado com dados do Censo da Educação Superior e de respostas ao questionário composto por variáveis socioeconômicas do ENADE).

O cálculo do CPC tem implicação direta no Índice Geral de Cursos (IGC), que também é uma espécie de medida de qualidade de instituições de nível superior. Este último índice leva em consideração a qualidade dos cursos de graduação e pós-graduação (mestrado e doutorado). Esses programas são avaliados pela CAPES com notas na escala de 1 a 7, com avaliação trienal. Já o CPC também tem avaliação trienal, apresentando seu resultado final em valores contínuos (que vão de 0 a 500) e em faixas (de 1 a 5).

Observa-se pela Tabela 1 a seguir que o curso de Administração com maior CPC em universidades é o da Universidade Federal de Santa Catarina (UFSC), com 4,446054; nos centros universitários, o maior é o do Centro Universitário Municipal de São José (USJ), com 4,312961. No entanto, quando se leva em consideração o tamanho da instituição, a UFSC tinha 2.014 matrículas no triênio 2007-2009, enquanto a USJ tinha, no mesmo triênio, somente 284 matrículas. 
Tabela 1 Cursos de Administração com CPC (Universidades de Santa Catarina/2007-2008-2009)

\begin{tabular}{|c|c|c|c|c|c|}
\hline Ano IGC & $\begin{array}{c}\text { Ano } \\
\text { Enade }\end{array}$ & IES & Sigla $\quad \nabla$ & CPC & Matrículas \\
\hline 2009 & 2009 & FUNDAÇÃO UNIVERSIDADE DO ESTADO DE SANTA CATARINA & UDESC & 2,55458 & - \\
\hline 2009 & 2009 & FUNDAÇÃO UNIVERSIDADE DO ESTADO DE SANTA CATARINA & UDESC & 4,243913 & 1058 \\
\hline 2009 & 2009 & UNIVERSIDADE REGIONAL DE BLUMENAU & FURB & 3,212261 & 1398 \\
\hline 2009 & 2009 & UNIVERSIDADE DA REGIÃO DE JOINVILLE & UNIVILLE & 2,568946 & 311 \\
\hline 2009 & 2009 & UNIVERSIDADE DA REGIÃO DE JOINVILLE & UNIVILLE & 2,238752 & 1148 \\
\hline 2009 & 2009 & UNIVERSIDADE DO OESTE DE SANTA CATARINA & UNOESC & 1,77942 & 119 \\
\hline 2009 & 2009 & UNIVERSIDADE DO OESTE DE SANTA CATARINA & UNOESC & 2,214394 & 381 \\
\hline 2009 & 2009 & UNIVERSIDADE DO OESTE DE SANTA CATARINA & UNOESC & 2,168606 & 333 \\
\hline 2009 & 2009 & UNIVERSIDADE DO OESTE DE SANTA CATARINA & UNOESC & 1,759815 & 111 \\
\hline 2009 & 2009 & UNIVERSIDADE DO OESTE DE SANTA CATARINA & UNOESC & 2,753019 & 232 \\
\hline 2009 & 2009 & UNIVERSIDADE DO OESTE DE SANTA CATARINA & UNOESC & 2,505795 & 110 \\
\hline 2009 & 2009 & UNIVERSIDADE DO OESTE DE SANTA CATARINA & UNOESC & 2,397357 & 415 \\
\hline 2009 & 2009 & UNIVERSIDADE DO OESTE DE SANTA CATARINA & UNOESC & 2,103626 & 401 \\
\hline 2009 & 2009 & UNIVERSIDADE DO OESTE DE SANTA CATARINA & UNOESC & 2,481772 & 98 \\
\hline 2009 & 2009 & UNIVERSIDADE DO VALE DO ITAJAÍ & UNIVALI & 2,602884 & 582 \\
\hline 2009 & 2009 & UNIVERSIDADE DO VALE DO ITAJAÍ & UNIVALI & 2,834888 & 1226 \\
\hline 2009 & 2009 & UNIVERSIDADE DO VALE DO ITAJAÍ & UNIVALI & 2,41921 & 281 \\
\hline 2009 & 2009 & UNIVERSIDADE DO VALE DO ITAJAÍ & UNIVALI & 3,045079 & 319 \\
\hline 2009 & 2009 & UNIVERSIDADE DO VALE DO ITAJAÍ & UNIVALI & 3,0806 & 139 \\
\hline 2009 & 2009 & UNIVERSIDADE DO CONTESTADO & UNC & 1,723574 & 396 \\
\hline 2009 & 2009 & UNIVERSIDADE DO CONTESTADO & UNC & 1,595434 & 176 \\
\hline 2009 & 2009 & UNIVERSIDADE DO CONTESTADO & UNC & 2,159106 & 206 \\
\hline 2009 & 2009 & UNIVERSIDADE DO CONTESTADO & UNC & 2,15349 & 285 \\
\hline 2009 & 2009 & UNIVERSIDADE DO CONTESTADO & UNC & 1,566625 & 160 \\
\hline 2009 & 2009 & UNIVERSIDADE DO CONTESTADO & UNC & 1,858715 & 176 \\
\hline 2009 & 2009 & UNIVERSIDADE DO EXTREMO SUL CATARINENSE & UNESC & 2,300404 & 927 \\
\hline 2009 & 2009 & UNIVERSIDADE DO SUL DE SANTA CATARINA & UNISUL & 3,943313 & 250 \\
\hline 2009 & 2009 & UNIVERSIDADE DO SUL DE SANTA CATARINA & UNISUL & 2,681761 & 214 \\
\hline 2009 & 2009 & UNIVERSIDADE DO SUL DE SANTA CATARINA & UNISUL & 2,577009 & 97 \\
\hline 2009 & 2009 & UNIVERSIDADE DO SUL DE SANTA CATARINA & UNISUL & 3,155755 & 1580 \\
\hline 2009 & 2009 & UNIVERSIDADE DO SUL DE SANTA CATARINA & UNISUL & 1,896668 & 134 \\
\hline 2009 & 2009 & UNIVERSIDADE DO SUL DE SANTA CATARINA & UNISUL & 1,94171 & 253 \\
\hline 2009 & 2009 & UNIVERSIDADE FEDERAL DE SANTA CATARINA & UFSC & 4,446054 & 2014 \\
\hline 2009 & 2009 & UNIVERSIDADE DO PLANALTO CATARINENSE & UNIPLAC & 2,423223 & 342 \\
\hline 2009 & 2009 & CENTRO UNIVERSITÁRIO DO ESPÍRITO SANTO & UNESC & 2,093258 & 236 \\
\hline 2009 & 2009 & CENTRO UNIVERSITÁRIO DO ESPIRITO SANTO & UNESC & 1,46063 & 240 \\
\hline 2009 & 2009 & UNIVERSIDADE COMUNITÁRIA DA REGIÃO DE CHAPECÓ & UNOCHAPECÓ & 2,297369 & 783 \\
\hline 2009 & 2009 & UNIVERSIDADE COMUNITÁRIA DA REGIÃO DE CHAPECÓ & UNOCHAPECÓ & 2,321697 & 47 \\
\hline 2009 & 2009 & FACULDADES INTEGRADAS DE CACOAL & UNESC & 1,098105 & 183 \\
\hline
\end{tabular}

Fonte: Adaptado pelos autores de MEC/INEP/DEED.

Tabela 2 Cursos de Administração com CPC (Centros Universitário de Santa Catarina/2007-20082009)

\begin{tabular}{|c|r|l|c|c|c|}
\hline Ano IGC & $\begin{array}{c}\text { Ano } \\
\text { Enade }\end{array}$ & \multicolumn{1}{|c|}{ IES } & Sigla & CPC & $\begin{array}{c}\text { Matrícula } \\
\mathbf{s}\end{array}$ \\
\hline 2009 & 2009 & CENTRO UNIVERSTTÁRIO PARA O DESENVOLVIMENTO DO ALTO VALE DO ITAJÁl & UNIDAVI & 2,855592 & 635 \\
\hline 2009 & 2009 & CENTRO UNIVERSITÁRIO PARA O DESENVOLVIMENTO DO ALTO VALE DO ITAJAI & UNIDAVI & 3,038689 & 133 \\
\hline 2009 & 2009 & CENTRO UNIVERSITÁRIO DE BRUSQUE & UNIFEBE & 2,544735 & 573 \\
\hline 2009 & 2009 & CENTRO UNIVERSITÁRIO DE JARAGUÁ DO SUL & UNERJ & 2,088091 & 848 \\
\hline 2009 & 2009 & CENTRO UNIVERSITÁRIO BARRIGA VERDE & UNIBAVE & 1,845727 & 256 \\
\hline 2009 & 2009 & CENTRO UNIVERSITÁRIO MUNICIPAL DE SÃO JOSÉ & USJ & 4,312961 & 284 \\
\hline
\end{tabular}

Fonte: Adaptado pelos autores de MEC/INEP/DEED. 
Em um estudo elaborado por Mainardes e Domingues (2010, p. 221) com alunos de graduação em Joinville/SC, "percebeu-se que os atributos de melhor desempenho na visão dos alunos, objetivo específico deste estudo, são relacionados à reputação do curso e da IES na sociedade e a valorização do curso no mercado de trabalho". O curso de graduação em Administração tem por finalidade a formação universitária e habilita à obtenção de grau acadêmico e ao exercício profissional. Fica, aqui, uma pergunta: como desenvolver o espírito científico e crítico na formação de futuros administradores?

\section{A PESQUISA E A PRODUÇÃO DO CONHECIMENTO}

O que é a pesquisa? Como se produz conhecimento científico? Essas são questões essenciais para alunos e professores que se preocupam com a pesquisa como assunto de sala de aula. Contudo, faz-se necessário, em primeiro lugar, termos claro que não existe uma única resposta. Existem diferentes respostas para as questões acima, que variam segundo as perspectivas e concepções assumidas por aqueles que se propõem a investigá-las. Nas palavras de Morin (2008, p. 20), "A ciência não é somente uma acumulação de verdades verdadeiras. Digamos mais, continuando Popper: é um campo sempre aberto onde se combatem não só as teorias, mas também os princípios da explicação, isto é, também visões de mundo e os postulados metafísicos".

Do ponto de vista epistemológico, existem aqueles que afirmam que pesquisa é o ato de se chegar a um retrato fiel e puro da realidade tal qual ela se apresenta. Também existem aqueles que acham que o conhecimento científico é a expressão de um processo de deduções lógicas formuladas sobre a realidade. Nós nos colocamos na compreensão de que a pesquisa deve procurar uma estreita relação entre o conhecimento, a realidade e a prática social. Aqui o conhecimento científico é referenciado na materialidade social e em sua dinâmica contraditória. É na dinâmica da práxis social que colocamos o pressuposto fundante do conhecimento científico. Nessa perspectiva, o conhecimento vai além da manifestação do aparente. Assim, cabe à ciência revelar o sentido, a essência dos fenômenos, tentando apreender suas manifestações e penetrar naquilo que está além de sua simples manifestação aparente.

O ponto de partida é que a realidade não é transparente - se fosse, por que então investigá-la? O fenômeno aparente que pretendemos investigar indica uma essência mais profunda (causas, relações), mas não a desvenda imediatamente; faz-se necessário investigar, "mergulhar", examinar as partes, as relações que se estabelecem entre o objeto investigado e a 
totalidade social. Trata-se de trabalhar o particular, investigar determinado fenômeno e compreendê-lo em articulação com outros fatos mais gerais, universais. Todo fato a ser investigado não se constitui como uma esfera estanque, solta, mas é parte de uma determinada dinâmica e se ancorada na realidade social. Assim, a pesquisa é sempre a busca de algo novo que se quer descobrir ou o embate entre o já conhecido e o que se está por conhecer; leve-se em conta, porém, que o que se quer conhecer é de alguma forma determinado, em última instância, pela dinâmica da materialidade social.

Como a realidade é dinâmica, o ato de pesquisar também é o caminho para se desvendar e decifrar a aparência/essência da dialética do real, na qual a arte, o trabalho, a educação, a literatura e outros infindáveis campos também se constituem como caminhos legítimos na produção de conhecimento, porque buscam a compreensão do homem, de seu tempo histórico e da própria realidade.

\section{POR QUE PESQUISAR NA GRADUAÇÃO?}

A pesquisa se constitui como atividade principal da ciência, permitindo-nos a compreensão e a produção de um conhecimento aproximativo da realidade. Contudo, pesquisar não significa somente desvendar algo, mas também construir algo novo, que não existia antes.

No caso da graduação, a pesquisa deve ser articulada ao ensino e à extensão. Digamos que o ensino reflete determinadas teorias originadas da práxis social e que tem sempre a possibilidade de questionar teorias, a sociedade ou o tempo histórico em que foram produzidas, gerando debates e novas discussões. Já na extensão, pode-se testar a veracidade de teorias, uma vez que diz respeito à aplicação do saber elaborado, constituindo-se como uma extensão da vida acadêmica. Contudo, é na pesquisa que se produzem saberes; isso a constitui como a instância privilegiada da articulação teoria/prática.

Podemos relacionar esse tópico às diferenças entre o pescador e o mergulhador. Os alunos que não tiveram a oportunidade de pesquisar na graduação são como o pescador: aprende a manusear a vara e o anzol e pode pescar peixes de variadas espécies; contudo, só pode pescar os peixes de acordo com o tamanho da vara e a espessura do anzol. Ele tem, portanto, limitações impostas pela estrutura e pela dinâmica de seus instrumentos. Já os alunos que tiveram experiência com a pesquisa são como o mergulhador: vão além da superfície, "mergulham", vão até as profundezas, confrontam-se com a realidade sem 
limitações de instrumentos, seja pelo simples prazer de descobrir, seja porque buscam pérolas que somente os mergulhos em águas profundas podem revelar.

A perspectiva da pesquisa em sala de aula implica romper os preconceitos de que o pesquisador encontra-se em um pedestal inacessível aos pobres mortais. Implica, sobretudo, confiança em si mesmo e nos alunos como pessoas autônomas e capazes de produzir saber. Nesse particular, faz-se necessário dar um passo adiante. Faz-se, sobretudo, necessário compreender que o conhecimento não é algo dado espontaneamente, mas que resulta de um esforço sistemático de apreensão, re-elaboração e problematização. Trata-se, enfim, do esforço na busca do sentido das teorias, das experiências, da identidade profissional etc.

O desafio é incorporar a pesquisa como alternativa viável e cotidiana ao processo ensino-aprendizagem em sala de aulas da graduação, de forma que passe a se constituir como princípio educativo e, sobretudo, como atividade vital no despertar do prazer em conhecer.

O homem evolui não somente no seu aparelho neurofisiológico, mas também em sua alma e espírito, o que o leva a descobrir questões que envolvem a cultura e a sociedade, gerando teorias, quebrando ou reforçando paradigmas. Segundo Minayo (1994), o conhecimento científico não reflete as leis da natureza; traz com ele um universo de teorias, de ideias, de paradigmas, o que nos remete, por um lado, para as condições bioantropológicas do conhecimento (porque não há espírito sem cérebro) e, por outro, para o enraizamento cultural, social e histórico das teorias (MORIN, 2008, p. 21).

\section{COMO INICIAR UMA PESQUISA}

\subsection{O processo de preparação}

No cotidiano da sala de aula em qualquer disciplina, percebem-se as dificuldades que cercam os alunos, principalmente a de escrever. Logo há a percepção coletiva de que grande parte dessa problemática é proveniente da falta de leitura. Essa constatação antecede as seguintes questões: Como começar a escrever? Como escrever sem ler? Nesse quesito, Garcia (2002, p. 301) assegura: “Aprender a escrever é, em grande parte, se não principalmente, aprender a pensar, aprender a encontrar ideias e a concatená-las, pois, assim como não é possível dar o que não se tem, não se pode transmitir o que a mente não criou ou não aprisionou".

A partir da constatação dessa deficiência, inicialmente a aula é dedicada à reflexão de como formar hábitos de leitura e sua importância na formação do futuro administrador. Ler 
parece um ato simples e, apesar disso, há uma enorme dificuldade que se reflete, certamente, na qualidade da escrita, pois trata-se de atos intrinsecamente relacionados.

Nesse processo inicial, algumas sugestões são dadas: organizar um cronograma de estudo, fixando-o em um local visível e de fácil acesso; criar o hábito de dedicar pelo menos trinta minutos por dia, o mínimo recomendado, para a leitura do tema de interesse de cada aluno, em paralelo aos estudos das outras disciplinas cursadas no semestre; escolher um ambiente propício a essa atividade, longe da televisão e de barulhos; planejar horários de estudos durante a semana, de segunda a sexta, para aproveitamento do tempo e para que o final de semana esteja livre para a família, o lazer etc. É imprescindível que o assunto a ser estudado tenha partido realmente do interesse do aluno, para que haja prazer na leitura.

\subsection{O processo de produção do conhecimento}

\subsubsection{A proceso de produção}

O primeiro trabalho a ser desenvolvido numa disciplina é um artigo científico, sobre o qual os alunos são orientados em todas as suas etapas, pois é a partir dessa elaboração que serão exercitadas as capacidades de análise e reflexão, além das habilidades de leitura e escrita:

O artigo é a apresentação sintética, em forma de relatório escrito, dos resultados de investigações ou estudos realizados a respeito de uma questão. O objetivo fundamental de um artigo é o de ser um meio rápido e sucinto de divulgar e tornar conhecidos, através de sua publicação em periódicos especializados, a dúvida investigada, o referencial teórico utilizado (as teorias que serviam de base para orientar a pesquisa), a metodologia empregada, os resultados alcançados e as principais dificuldades encontradas no processo de investigação ou na análise de uma questão. (BARBA, 2011, $\mathrm{s} / \mathrm{p})$.

O primeiro passo a ser dado após a escolha de um tema de interesse é a busca por autores que tratam da mesma temática, seja em livros, seja em periódicos, seja no meio virtual (uma sugestão é o site www.scielo.org.br). É feito um apanhado teórico em várias fontes; a busca também pode ser documental, através de textos que ainda não foram analisados, como jornais, revistas, relatórios etc., além de uma aula específica de como fazer pesquisa online em bases de dados de literatura indexada (MATOS; VIEIRA, 2002).

Segundo Santos (1999), é importante lembrar que o aluno não terá que "inventar a roda", e sim interpretar, analisar, confrontar com outros autores o que já foi escrito, descoberto, estudado e analisado. Nesse contexto, o professor é chamado a participar da 
comunicação/relação com os alunos, vivenciando o papel de agente facilitador do diálogo educacional. Nas palavras de Freire (2002, p. 12),

Se, na experiência da minha formação, que deve ser permanente, começo por aceitar que o formador é o sujeito em relação a quem me considero objeto, que ele é o sujeito que me forma e eu, o objeto por ele formado, me considero como um paciente que recebe conhecimentos-conteúdosacumulados pelo sujeito que sabe e que são a mim transferidos. [...] É neste sentido que ensinar não é transferir conhecimentos, conteúdos nem formar é ação pela qual um sujeito criador dá forma, estilo ou alma a um corpo indeciso e acomodado. Não há docência sem discência, as duas se explicam e seus sujeitos, apesar das diferenças que os conotam, não se reduzem à condição de objeto, um do outro. Quem ensina aprende ao ensinar, e quem aprende ensina ao aprender.

Há grande valorização de todo o material trazido pelo aluno, pois é muito importante que as orientações sejam em um contato ao vivo, em que muitas dúvidas podem ser esclarecidas. Na maioria das vezes, o aluno tem dificuldade de expressar o seu pensamento, então ele coloca suas ideias por meio da fala, e o processo de orientação pode ajudá-lo a contextualizar suas indagações e dúvidas. Vale ressaltar, porém, que o maior empenho será realmente do próprio aluno. As ideias serão as dele; a orientação somente ajuda a organizá-las e a pontuá-las por meio da linguagem escrita. As sessões de orientação ocorrem durante todo o processo de construção do artigo, até a sua finalização.

\subsubsection{A utilização das regras}

Durante o processo ensino-aprendizagem, o aluno tem o conhecimento das regras de normatização do trabalho científico. As regras básicas da American Psychological Association (APA) e da Associação Brasileira de Normas e Técnicas (ABNT) devem ser consultadas sempre quando necessário, na elaboração do artigo.

\subsection{O projeto de pesquisa}

Minayo (1994) define um projeto de pesquisa como a elaboração de um mapa a ser seguido durante todo um processo de investigação. É nessa fase que o aluno, após fazer uma análise mais ampla sobre um determinado tema exposto no artigo científico, colocará em prática a sua capacidade de síntese na construção do projeto de pesquisa.

Outra função importante do projeto, segundo a autora supracitada, é deixar claro para o próprio investigador os rumos que serão tomados na investigação, que se traduzem, por 
exemplo, nas seguintes perguntas: o que estudar? Qual é a relevância? Qual é o tempo necessário? Como será feita a pesquisa? Para que fazer a pesquisa?

De acordo com Bastos (2003), o projeto de pesquisa não obedece a um padrão rígido quanto aos seus elementos constitutivos; ele pode variar, e sua complexidade está diretamente relacionada com o tipo e os objetivos da pesquisa. São elementos básicos do projeto: título, problema e delimitação do objeto, objetivos, justificativa, definição dos termos, cronograma e referências. Todos esses itens são analisados, estudados e exemplificados em sala de aula, para que o aluno compreenda e siga em frente com a formatação de sua proposta de investigação.

Para a elaboração do projeto, é necessário, contudo, que se tenha uma questão de pesquisa. A pergunta de partida será o instrumento que vai guiar o aluno e é a razão pela qual ele irá fazer a investigação. É, portanto, o principius movens da pesquisa.

Já o ponto de partida para a elaboração e o desenvolvimento do projeto de pesquisa é a problematização, pois "O tema de uma pesquisa indica uma área de interesse a ser investigada. Trata-se de uma investigação ainda bastante ampla” (MINAYO, 1994, p. 37). Sendo assim, é necessária uma maior delimitação, um recorte do tema de interesse do aluno. Ao formularmos perguntas ao tema, estaremos formulando, então, a definição do objeto de investigação.

Durante toda a elaboração do projeto de pesquisa o aluno é orientado individualmente, recebendo os suportes didático, teórico e prático necessários para a elaboração de seu trabalho. De acordo com Tassigny $(2010$, p. 71$)$ :

A pesquisa se constitui como atividade principal da Ciência que nos permite a compreensão e a produção de um conhecimento aproximativo da realidade. Contudo, pesquisar não significa somente desvendar algo, mas também a produção de conhecimentos que pode se fazer pressuposto de uma determinada ação.

\section{CONSIDERAÇÕES FINAIS}

Este artigo, além de revelar a importância da prática da pesquisa para a formação do aluno de Administração, também teve a preocupação de fundamentar o que se entende por ciência e pela práxis da pesquisa. Principalmente, exemplificou-se como se dá esse processo em sala de aula, como uma mediação imprescindível ao processo ensino-aprendizagem. 
Nessa mesma direção, ressaltou de que forma o professor pode trabalhar como agente facilitador desse processo educacional, mediando a comunicação e o diálogo com o aluno, sobretudo, por intermédio da participação ativa nas sessões de orientação.

Destacou-se ainda que, em todo o processo relatado neste artigo para a produção do conhecimento, em primeiro lugar encontra-se o comprometimento do próprio aluno no desenvolvimento de sua aprendizagem.

A experiência aqui relatada reflete uma dinâmica de construção e desconstrução, elaborações e reelaborações, bem como reflexões sobre o significado do processo de ensinar e aprender, a partir de conhecimentos produzidos através da pesquisa científica realizada no contexto da sala de aula. Buscou-se mostrar, neste exíguo espaço de reflexão acadêmica, alguns diminutos flashes sobre a atividade docente. Estes focalizam e, de certo modo, destacam nuances do cotidiano de uma práxis pedagógica que descobriu, já há certo tempo, o fascínio e o encanto propiciados pelo ambiente de pesquisa e construção da sala de aula, o qual apenas favorece a aprendizagem.

Por fim, acredita-se que não existe uma aula igual à outra, pois, como dizia um célebre pré-socrático, uma experiência nunca se repete, não é nunca a mesma, pois, obviamente, o docente não é mais o mesmo (mesmo que sendo a mesma pessoa), a sala de aula é diferente da do dia anterior, e os discentes, sendo os mesmos da caderneta do dia anterior, não são mais os mesmos... Assim, os alunos e o professor cotidianamente descobrem novos cenários e vislumbram novas possibilidades de pesquisa, valorizando a experiência vivenciada e o significado a ela atribuído para o processo de ensino-aprendizagem.

Também a escuta do aluno é fundamental: seus interesses epistemológicos, suas questões etc. "Aprender a aprender" e "aprender a fazer" têm sido conjugações fiéis dessa proposta didática e, como tais, têm sido "demarcadores de águas" na aprendizagem do graduando de Administração.

\section{AGRADECIMENTOS}

Sinceros agradecimentos à Fundação Cearense de Amparo à Pesquisa (FUNCAP) pelo fomento à pesquisa. 


\section{REFERÊNCIAS}

ARRAIS NETO, E. Mundialização e crise do capital: a relação dialética entre essência e fenômeno na constituição real do mundo do trabalho. In: MENEZES, A. M. D.;

FIGUEIREDO, F. F. (Org.). Trabalho, sociabilidade e educação: uma crítica à ordem do capital. Fortaleza: UFC, 2003. (Coleção Diálogos Intempestivos).

BARBA, C. H. de. Orientações básicas na elaboração do artigo científico. Disponível em: $<$ http://www.unir.br/html/pesquisa/Pibic/Elaboracao\%20de\%20Artigo\%20Cientifico2006.doc >. Acesso em: 8 de maio de 2011.

BASTOS, N. M. G. Introdução à metodologia do trabalho acadêmico. Fortaleza: Universidade de Fortaleza, 2003.

BRASIL. Conselho Nacional de Educação (CNE). Resolução $n^{\circ} 1$, de 2 de fevereiro de 2004. Brasília: Ministério da Educação, 2004.

. Lei $n^{\circ}$ 9.394, de 20 de dezembro de 1996. Lei de Diretrizes e Bases da Educação Nacional. Brasília, DF: 1996.

CHESNAIS, F. A mundialização do capital. São Paulo: Xamã, 1996.

FREIRE, P. Pedagogia da autonomia: Saberes necessários à prática educativa. 25 ed. São Paulo: Paz e Terra, 2002.

GARCIA, O. M. Comunicação em prosa moderna. 21 ed. Rio de Janeiro: Loyola, 2002.

MAINARDES, E.W; DOMINGUES; M. J. C. de S. Qualidade de cursos de Administração e Instituições de Ensino Superior em Joinville-SC: um estudo sobre os fatores relacionados ao mercado de trabalho na percepção dos alunos. Revista Brasileira de Gestão de Negócios, vol. 12, n. 35, p. 208-223, 2010.

MATOS, K. S. L. de; VIEIRA, S. L. Pesquisa educacional o prazer de conhecer. 2. ed. Fortaleza: Universidade Federal do Ceará, 2002.

MINAYO, M. C. Pesquisa social: teoria, método e criatividade. Petrópolis: Vozes, 1994.

MORIN, E. M. Ciência com ciência. Trad. de Maria Gabriela de Bragança e Maria da Graça Pinhão. Portugal: Publicações Europa-América, 2008.

SANTOS, A. R. dos. Metodologia científica: a construção do conhecimento. 2ed. Rio de Janeiro: DP\&A, 1999.

TASSIGNY, M. M. A importância da pesquisa na graduação de Psicologia: práxis formadora do sujeito investigador. In: TASSIGNY, M. M.; SAMPAIO, P. P. (Orgs.). Temas em Psicologia I: experiências em pesquisa. Fortaleza: Universidade de Fortaleza, 2010. p. 65-78. 